\title{
Relationships between addictive Facebook use, depressiveness, insomnia, and positive mental health in an inpatient sample: A German longitudinal study
}

\author{
JULIA BRAILOVSKAIA ${ }^{1 *}$, ELKE ROHMANN ${ }^{2}$, HANS-WERNER BIERHOFF $^{2}$, JÜRGEN MARGRAF ${ }^{1}$ and \\ VOLKER KÖLLNER ${ }^{3}$ \\ ${ }^{1}$ Mental Health Research and Treatment Center, Ruhr-Universität Bochum, Bochum, Germany \\ ${ }^{2}$ Department of Social Psychology, Ruhr-Universität Bochum, Bochum, Germany \\ ${ }^{3}$ Department of Psychosomatic Medicine, Rehabilitation Center Seehof, Federal German Pension Agency, \\ and Psychosomatic Rehabilitation Research Group, Charité - Universitätsmedizin Berlin, Berlin, Germany
}

(Received: May 26, 2019; revised manuscript received: September 27, 2019; second revised manuscript received: October 27, 2019; accepted: November 3, 2019)

\begin{abstract}
Background and aims: Individuals with high level of negative mental health often tend to use the social platform Facebook to escape from daily stress. They are at risk to develop an emotional bond to Facebook linked to a need to stay permanently online. The current work investigated addictive use of Facebook and its conceptual framework in clinical context. Methods: In a longitudinal study design, duration of daily use of Facebook, addictive Facebook use, depressiveness, insomnia, and positive mental health (PMH) were assessed in a sample of 349 inpatients $\left[M_{\text {age }}\left(S D_{\text {age }}\right)=50.13(9.41)\right]$ of a psychosomatic rehabilitation clinic in Germany over a period of on average 6 weeks. Results: Regression analyses revealed that duration of daily Facebook use at the first measurement time point (T1) served as significant positive predictor of addictive Facebook use at the second measurement time point (T2). Addictive Facebook use (T1) significantly positively predicted depressiveness and insomnia (T2). Its prediction of PMH (T2) was significantly negative. Mediation analyses showed that PMH (T1) partially mediated the association between addictive Facebook use (T1) and depressiveness (T2), and fully mediated the relationship between addictive Facebook use (T1) and insomnia (T2). Discussion and conclusions: Current longitudinal results indicate that addictive Facebook use might negatively impact the recovery process of inpatients. Thus, it might be relevant to assess and consider addictive Facebook use in the clinical context. Therapeutic interventions are suggested to focus on the enhancement of inpatients' PMH level, which may buffer the negative effect of problematic Facebook use.
\end{abstract}

Keywords: addictive Facebook use, duration of daily Facebook use, depressiveness, insomnia, positive mental health, longitudinal study

\section{INTRODUCTION}

In the past years, a lot of research focused on negative consequences of intensive use of social networking sites (SNSs) that nowadays belong to daily life of many people (Frost \& Rickwood, 2017; Kircaburun \& Griffiths, 2018; Marino, Gini, Vieno, \& Spada, 2018; Tromholt, 2016; Twenge, Joiner, Rogers, \& Martin, 2018). One of those consequences is the development of an emotional need to stay permanently online linked to a psychological unease when the SNS has to be left temporarily. This consequence is described as problematic or addictive use of social media (Andreassen et al., 2016; Bányai et al., 2017).

Having more than 2.4 billion members and more than 1.59 billion daily users (Roth, 2019), Facebook is currently the largest SNS worldwide. Its high popularity inter alia is based on many functions that this social platform offers to its users (Brailovskaia \& Margraf, 2019). While other SNSs often focus on specific tools (e.g., users of Instagram mostly engage in photo-sharing, users of Twitter express themselves typically by short-written tweets, and use of Snapchat means a short-time sharing of content), the Facebook umbrella combines a larger number of different functions such as sharing of written content by public status updates and private messages, sharing common interests in a variety of discussion groups, uploading and sharing of photos and videos, and playing online games (Brailovskaia \& Margraf, 2018; Kuss \& Griffiths, 2017). The social interaction and self-presentation enabled by the large number of different functions of Facebook are often accompanied by positive feedback from other users in the form of "likes" and supportive comments. This feedback that has frequently a rewarding impact on the users contributes to their experience of gratification (Papacharissi \& Mendelson, 2011; Raacke \& Bonds-Raacke, 2008) linked to satisfaction

\footnotetext{
* Corresponding author: Dr. Julia Brailovskaia; Mental Health Research and Treatment Center, Ruhr-Universität Bochum, Massenbergstr. 9-13, 44787 Bochum, Germany; Phone: +49 23432 21506; Fax: +49 23432 14169; E-mail: Julia.Brailovskaia@rub.de
}

This is an open-access article distributed under the terms of the Creative Commons Attribution-NonCommercial 4.0 International License, which permits unrestricted use, distribution, and reproduction in any medium for non-commercial purposes, provided the original author and source are credited, a link to the CC License is provided, and changes - if any - are indicated. 
of a variety of individual needs, such as the need to belong and to receive social support (Indian \& Grieve, 2014), as well as the need to be admired and popular (Brailovskaia \& Margraf, 2019).

However, this positive experience may also foster the development of an emotional bond to the social platform. Affected individuals tend to engage in excessive Facebook use to maintain the experience of gratification and to be further rewarded by positive feedback. This addictive use of social media may contribute to the development of addiction-like symptoms/characteristics (Błachnio et al., 2016; Brailovskaia \& Margraf, 2017; Casale \& Fioravanti, 2018), including salience (e.g., permanent thinking of Facebook), tolerance (e.g., to achieve the previous positive effect, time on Facebook is increased), mood modification (e.g., improved sentiment by Facebook activity), relapse (e.g., reverting to previous use pattern after ineffective attempts of reduction of Facebook use), withdrawal symptoms (e.g., growing nervousness and uneasiness without Facebook use), and conflict (e.g., interpersonal problems caused by permanent intensive Facebook use; Andreassen, Torsheim, Brunborg, \& Pallesen, 2012; Wilson, Fornasier, \& White, 2010).

The described symptoms/characteristics are similar to those defined for recognized forms of addiction (Griffiths, 2005). However, note that so far problematic or addictive use of social media - here represented by the platform Facebook - is not recognized as formal psychiatric disorder and is not integrated into the international classification systems (e.g., Diagnostic and Statistical Manual of Mental Disorders, 5th ed.; American Psychiatric Association, 2013). Moreover, a current debate focuses on the question whether the inclusion of problematic use of social media as a disorder might cause an (over)pathologization of a behavior that belongs to the daily life of many people worldwide (Billieux, Schimmenti, Khazaal, Maurage, \& Heeren, 2015; Rothen et al., 2018).

Despite the debate about the status of addictive use of social media, previous research provided empirical evidence about a close relationship between addictive Facebook use - a label that in the following will be used in the current study - and various variables of mental health. Addictive use of Facebook was described to be positively linked to use frequency of Facebook (Brailovskaia, Schillack, \& Margraf, 2018), to experience of daily stress (Brailovskaia, Teismann, \& Margraf, 2018b) and to insomnia (Atroszko et al., 2018; Koc \& Gulyagci, 2013). Its link to satisfaction with own physical state (Atroszko et al., 2018) and to positive mental health (PMH; i.e., emotional, social, and psychological well-being; Brailovskaia et al., 2018b) was negative. Particularly, persons with enhanced symptoms of depression (Błachnio, Przepiórka, \& Pantic, 2015; Brailovskaia, Schillack, et al., 2018; Hong, Huang, Lin, \& Chiu, 2014) and of anxiety (Atroszko et al., 2018; Brailovskaia \& Margraf, 2017; Koc \& Gulyagci, 2013) seem to be vulnerable to addictive Facebook use, which was explained as follows. Individuals concerned, on one hand, feel often overloaded by daily requirements in the offline world and therefore tend to social withdraw and isolation (Lovibond \& Lovibond, 1995). On the other hand, however, they have a high need for social support, attachment, and belonging (Brailovskaia, Schönfeld, et al., 2018; Zhang, Fang, Wu, \& Wieczorek, 2013). Satisfaction of those needs depressed and anxious individuals often search on Facebook, where they can avoid direct face-to-face contact (Brailovskaia, Schillack, et al., 2018). They were described to engage in intensive use of this SNS (e.g., writing of status updates and of comments), whereby they often disclose their sorrows and typically receive emotional support from their online friends (Sinclair \& Grieve, 2017; Wright et al., 2013). Furthermore, Facebook provides its users ample possibilities for planned and controlled positive self-presentation, which is often linked to recognition and popularity (Brailovskaia \& Bierhoff, 2016). This may be especially of advantage for users with high level of social anxiety, who often desire positive social feedback but are too shy to present their person in offline face-to-face interactions (Fernandez, Levinson, \& Rodebaugh, 2012).

The positive experiences made in social online interactions were found to contribute to the enhancement of life satisfaction and of subjective happiness (Brailovskaia \& Margraf, 2016); variables that often are at a low level in individuals with increased depression and anxiety symptoms. As a consequence, however, they are at an enhanced risk to develop a strong emotional bond to Facebook correlated with an obsessive desire to continuously participate in online activities to maintain these positive experiences (Andreassen et al., 2012; Brailovskaia, Schillack, et al., 2018; Marino et al., 2018). To satisfy this desire, affected persons tend to increase the time spent on Facebook and to neglect their responsibilities at home and at work. They often consider Facebook use as the main (or even only) means for mood modification. This habit, however, fosters interpersonal conflicts and therefore enhances negative symptoms of affected persons (Ryan, Chester, Reece, \& Xenos, 2014), inter alia contributing to depressiveness and insomnia (Koc \& Gulyagci, 2013).

In summary, especially individuals with high level of negative mental health tend to escape into the Facebook world from daily stress, where they gain positive experiences often missed offline and therefore may better manage their negative mood. This enhances their risk of addictive use of Facebook, which among others increases symptoms they already suffer from. The results of a recent study that - for the first time - considered addictive Facebook use in clinical context (Brailovskaia, Margraf, \& Köllner, 2019) support this conclusion. In a sample of inpatients who were mostly diagnosed with affective disorders and anxiety disorders, the mean level of addictive Facebook use was remarkably higher than previous findings from mostly young, mentally healthy student samples (e.g., Andreassen et al., 2013; Brailovskaia \& Margraf, 2017; Brailovskaia, Schillack, et al., 2018). The authors emphasized that addictive Facebook use - that seems not to be a symptom of other disorders, but rather an additional problem which inpatients are dealing with - might negatively impact the recovery process of inpatients and therefore should be made a topic of discussion when planning therapeutic treatment. However, due to the cross-sectional design of this study, no longitudinal conclusions about addictive Facebook use in the clinical context could be drawn. In addition, no further 
variables of mental health than the inpatients' diagnoses were assessed. Therefore, dependencies between addictive Facebook use and mental health in inpatients remain unclear.

Lack of this evidence impedes an adequate assessment of the risk of addictive Facebook use for the clinical routine. Therefore, considering the high popularity of this SNS (Roth, 2019) and the hypothesized negative effect of problematic Facebook use (Brailovskaia et al., 2019; Ryan et al., 2014), we aimed to investigate addictive Facebook use and its framework in a longitudinal inpatient study (i.e., two measurement time points: at the beginning of the clinical stay, T1; at the end of the clinical stay, T2). The results should contribute to the risk assessment of addictive Facebook use for inpatients' mental health and recovery process.

First, we focused on addictive Facebook use. To the best of our knowledge, to date, changes of addictive Facebook use have been investigated longitudinally only once. In a student sample, over a period of 1 year, no significant change of the mean level of addictive Facebook use was found (Brailovskaia \& Margraf, 2017). However, it remains unclear whether these findings may be replicated for clinical inpatients, who may differ from mentally healthy students in many respects. Particularly, they suffer from mental disorders for which they are treated in a clinical setting (that means that they have to leave their familiar environment for the duration of the treatment), and they often are older than students. Considering the lack of previous longitudinal findings from clinical samples that would allow the derivation of a well-founded hypothesis, the following research question was formulated:

Does the level of addictive Facebook use change between $\mathrm{T} 1$ and $\mathrm{T} 2$ in the context of a rehabilitation clinic? (Research Question).

Note that the derivation of a well-founded hypothesis is further complicated by the fact that inpatients were not in their familiar environment and had to adapt to an inpatient clinic. Therefore, the institutional background constitutes a specific context. This background is in correspondence with the study goal to investigate the comparability of the results based on a student sample with inpatients of a psychosomatic rehabilitation clinic. Furthermore, the inpatients were treated for disorders like affective disorders, anxiety disorders, or adjustment disorder. Therefore, the study is about the change of Facebook use over time when being in a psychosomatic clinic treated for one or the other disorder. Note that this context is widespread and worthwhile to study because thousands of individuals are admitted to psychosomatic rehabilitation clinics every week (Köllner, 2014; Linden, 2014; Muschalla, Kessler, Schwantes, \& Linden, 2013). Therefore, the study goal is highly relevant for applied purposes, which are related to the specific context of rehabilitation clinics.

Second, we considered the relationship between addictive Facebook use and duration of the use of this SNS. In accordance with earlier cross-sectional findings that suggested that intensive Facebook use may contribute to the development of addictive tendencies (Brailovskaia, Schillack, et al., 2018), we expected duration of daily
Facebook use at $\mathrm{T} 1$ to positively predict addictive Facebook use at T2 (Hypothesis 1). Figure 1a visualizes this hypothesis.

Third, we focused on the relationship between addictive Facebook use and mental health. Thereby, we followed previous theoretical background, which in accordance with the dual-factor model of mental health (Keyes, Shmotkin, \& Ryff, 2002) emphasized that to provide a complete picture of mental health, it is important to focus on both of its interrelated but separate dimensions: negative and positive (Teismann, Brailovskaia, Siegmann, et al., 2018; Trompetter, Lamers, Westerhof, Fledderus, \& Bohlmeijer, 2017). Thus, we included both dimensions in our investigation. Based on findings referring to relationships of addictive Facebook use in healthy samples (e.g., Atroszko et al., 2018; Błachnio et al., 2015; Koc \& Gulyagci, 2013), the negative dimension was operationalized by depressiveness and insomnia in which clinical inpatients with different diagnoses often suffer from (e.g., Abad \& Guilleminault, 2005; Zisook et al., 2006). Previous cross-sectional research indicated that individuals with enhanced scores of addictive Facebook use often engage in excessive Facebook activity at night inter alia because they lose control of their usage time, but also because at night the probability to be interrupted while using Facebook is lower than during daytime. This often results in late rising times and bedtimes as well as in poor sleep quality and therefore might foster the development of insomnia (Andreassen et al., 2012; Wolniczak et al., 2013). Insomnia, however, may negatively impact the recovery process of the inpatients and enhance their suffering. Following Brailovskaia et al. (2018b), the positive dimension was operationalized by the general construct $\mathrm{PMH}$ that combines emotional, psychological, and social aspects of well-being (see Lukat, Margraf, Lutz, van der Veld, \& Becker, 2016). Regarding previous concerns about the negative effect of problematic Facebook use on mental health (Brailovskaia et al., 2019; Ryan et al., 2014), we assumed addictive Facebook use at T1 to positively predict depressiveness at T2 (Hypothesis 2a) and insomnia at T2 (Hypothesis 2b). Its predictive effect on PMH at T2 was expected to be negative (Hypothesis $2 c$ ). All three hypotheses are visualized in Figure $1 \mathrm{~b}-\mathrm{d}$.

Earlier research repeatedly emphasized the protective effect of PMH in different populations. For example, in a cross-sectional study as well as in a longitudinal study, PMH was found to buffer the effect of depression symptoms on suicide ideation in student samples (Siegmann et al., 2017; Teismann, Forkmann, et al., 2018). In a further student sample, PMH significantly mediated the impact of cyberbullying on suicide ideation and suicide behavior (Brailovskaia, Teismann, \& Margraf, 2018a). Several studies described PMH to serve as an important predictor of remission of mental disorders, such as specific phobia, panic disorder and agoraphobia in community samples (Lukat, Becker, Lavallee, van der Veld, \& Margraf, 2017; Trumpf, Becker, Vriends, Meyer, \& Margraf, 2009) and in outpatients (Teismann, Brailovskaia, Totzeck, Wannemüller, \& Margraf, 2018). On this background, we hypothesized that $\mathrm{PMH}$ could mediate the relationship between addictive Facebook use and variables of negative 
(a)

\begin{tabular}{|l|c|c|}
$\begin{array}{l}\text { Duration of daily } \\
\text { Facebook Use T1 }\end{array}$ & + & $\begin{array}{c}\text { Addictive } \\
\text { Facebook Use T2 }\end{array}$ \\
\cline { 3 - 3 } &
\end{tabular}

(b)

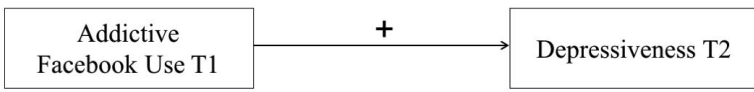

(c)

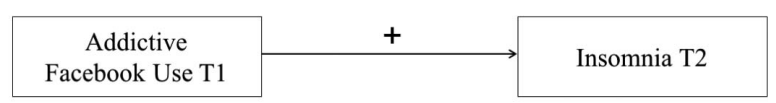

(d)

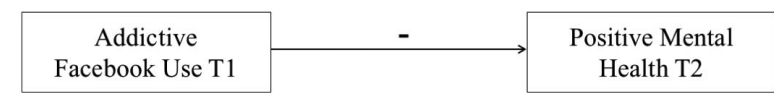

Figure 1. Visualization of Hypothesis 1 and Hypothesis 2: (a) Hypothesis 1; (b) Hypothesis 2a; (c) Hypothesis 2b; (d) Hypothesis $2 c$

(a)

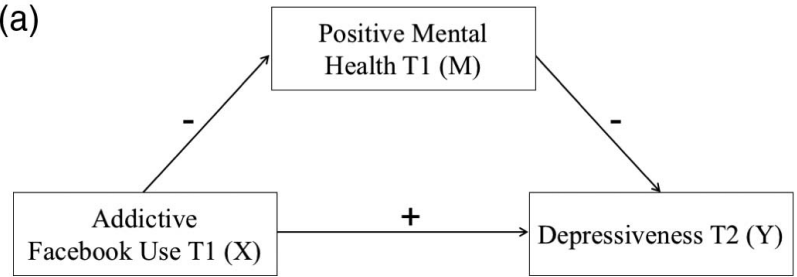

(b)

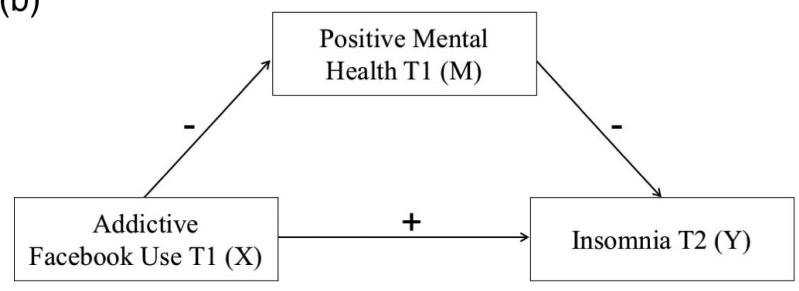

Figure 2. Visualization of Hypothesis 3: (a) Hypothesis 3a; (b) Hypothesis $3 b$

dimension of mental health. Therefore, PMH might serve as supportive factor of the inpatients' recovery process. Thus, we assumed that PMH at T1 mediates the positive relationship between addictive Facebook use at T1 and depressiveness at T2 (Hypothesis 3a), as well as between addictive Facebook use at T1 and insomnia at T2 (Hypothesis 3b). Figure 2 visualizes both hypotheses.

\section{METHODS}

\section{Participants}

The 349 Facebook users $\left[M_{\text {age }}\left(S D_{\text {age }}\right)=50.13(9.41)\right.$, range: $19-71 ; 70.2 \%$ women; all employed; $65.9 \%$ married] who participated in this study were inpatients of a large psychosomatic rehabilitation clinic in Germany. Such clinics typically treat individuals who suffer from diagnoses like affective disorders, anxiety disorders, adjustment disorder, and somatic symptom disorder longer than 6 months and therefore are restricted in occupational and social participation. The typical duration of clinical stay is 5-6 weeks (Köllner, 2014; Linden, 2014; Muschalla et al., 2013). In the current clinic, the treatment focus was on cognitive-behavioral psychotherapy, which included single and group settings, supplemented by sport and occupational therapy. At admission, all patients are indicated to reduce their use of technical devices and to engage in offline social interactions with other inpatients at common areas of the clinic (e.g., in the garden and at sofa corners). The main diagnoses in the current sample were affective disorders $(63 \%)$, followed by anxiety disorders $(20.1 \%)$, adjustment disorder $(16.3 \%)$, and somatic symptom disorder $(0.6 \%)$. On average, participants stayed 41.65 days $(S D=7.63$; range: $21-84$ ) at the psychosomatic clinic.

\section{Measures}

Depressiveness. Depressiveness was assessed with the German version of the Beck Depression Inventory-II (Hautzinger, Keller, \& Kühner, 2009). The 21 items represent different symptoms of depressiveness (e.g., "sadness," "pessimism," and "loss of pleasure"). The level of severity of the single symptoms over the past 2 weeks is rated on a 4 -point Likert scale $(0=$ not present, $3=$ severe $)$. To assess the level of depressiveness, the sum of the ratings of the 21 items is calculated. Current reliability: Cronbach's $\alpha_{\mathrm{T} 1}=$ $.92, \alpha_{\mathrm{T} 2}=.94$; retest reliability (6 weeks): $r_{\mathrm{T} 1 \mathrm{~T} 2}=.66$.

Insomnia. The Insomnia Severity Index (Bastien, Vallières, \& Morin, 2001) assessed individual perception of insomnia over the past 2 weeks. It contains seven items (e.g., "difficulty staying asleep") rated on a 5-point Likert scale (range: $0-4$ ). The sum of the ratings of the seven items indicates the level of insomnia. Current reliability: $\alpha_{\mathrm{T} 1}=$ $.89, \alpha_{\mathrm{T} 2}=.91$; retest reliability $(6$ weeks $): r_{\mathrm{T} 1 \mathrm{~T} 2}=.70$.

Positive Mental Health (PMH). The unidimensional Positive Mental Health Scale (PMH Scale; Lukat et al., 2016) was included to measure PMH. The nine items (e.g., "I feel that I am actually well equipped to deal with life and its difficulties") are rated on 4-point Likert scale $(0=d o$ not agree, $3=$ agree $)$. The level of $\mathrm{PMH}$ was assessed by the sum of the ratings of the nine items. Current reliability: $\alpha_{\mathrm{T} 1}=.88, \alpha_{\mathrm{T} 2}=.93$; retest reliability (6 weeks): $r_{\mathrm{T} 1 \mathrm{~T} 2}=.65$.

Daily Facebook use. Participants were asked to rate the duration of their daily Facebook use on a 7-point Likert scale $(1=$ less than $5 \mathrm{~min}, 7=$ more than $180 \mathrm{~min})$. Current retest reliability ( 6 weeks): $r_{\mathrm{T} 1 \mathrm{~T} 2}=.68$.

Addictive Facebook use. The brief version of the Bergen Facebook Addiction Scale (Andreassen et al., 2012) measured addictive Facebook use over a time frame of the last year with six items (e.g., "Used Facebook in order to forget about personal problems?") rated on a 5-point Likert scale $(1=$ very rarely, $5=$ very often $)$. Each item indicates one of the six core features of addictive Facebook use (i.e., salience, tolerance, mood modification, relapse, withdrawal, and conflict). The sum of the ratings of the six items 
indicates the level of addictive Facebook use. Current reliability: $\alpha_{\mathrm{T} 1}=.90, \alpha_{\mathrm{T} 2}=.91$; retest reliability (6 weeks): $r_{\mathrm{T} 1 \mathrm{~T} 2}=.83$.

In general, Cronbach's $\alpha$ and retest reliability were very good for each measure. All retest correlation measures were statistically significant. For all used instruments, higher values indicate higher level of the measured variable.

\section{Procedure}

Data were collected as part of diagnostic routine by a computer survey at two measurement time points: at the first day of inpatients' admission at the clinic (T1), and at the last day of the inpatients' clinical stay, when stay was no longer than 42 days (T2); if inpatients stayed longer than 42 days at the clinic, then the survey was completed at day 42. Thus, the time span between $\mathrm{T} 1$ and $\mathrm{T} 2$ was on average 6 weeks (days: $M=38.58, S D=3.85$; range: 21-42). The investigation period covered from July 2018 to January 2019. A priori conducted power analyses $\left(\mathrm{G}^{*}\right.$ Power program, version 3.1) indicated that a sample size of at least $N=200$ was required for valid results (power $>.80, \alpha=.05$; cf. Mayr, Erdfelder, Buchner, \& Faul, 2007).

\section{Statistical analyses}

Statistical analyses were conducted with the Statistical Package for the Social Sciences (SPSS, New York, NY, USA) 24 and the macro Process version 2.16.1 (www. processmacro.org/index.html).

All variables of interest were normally distributed (i.e., all coefficients of skewness and kurtosis within range of \pm 2 ; George \& Mallery, 2010; Gravetter \& Wallnau, 2014). First, repeated measures analyses of variance (within-subject ANOVAs) assessed changes of the included variables between T1 and T2 (see Research Question). Then, the relationship between all variables was investigated by zero-order bivariate correlations. Next, four 2-step hierarchical regression analyses $(95 \% \mathrm{CI})$ were calculated. In the first regression model, age and gender were included as control variables in Step 1. In Step 2, duration of daily Facebook use at T1 was added. Addictive Facebook use at T2 was considered as the dependent variable (see Hypothesis 1). In the other three regression models, age and gender served again as control variables in Step 1. In Step 2, addictive Facebook use at T1 was added. Depressiveness at T2, insomnia at T2, and PMH at T2 were, successively, considered as the dependent variable (see Hypotheses $2 a-2 c$ ). In all regression models, there was no violation of multicollinearity (i.e., all values of tolerance $>.25$, all variance inflation factor values $<5$; Urban \& Mayerl, 2006). Finally, two mediation analyses (Process: model 4) were calculated. Both included addictive Facebook use at $\mathrm{T} 1$ as predictor $(\mathrm{X})$ and $\mathrm{PMH}$ at $\mathrm{T} 1$ as mediator $(\mathrm{M})$. Age and gender, which were considered as control variables, were included as covariates. In the first analysis, depressiveness at $\mathrm{T} 2$ served as outcome (Y), whereas insomnia at T2 was included as outcome variable in the second analysis (see Hypothesis $3 a$ and Hypothesis $3 b$ ). In both mediation models, the basic relationship between predictor and outcome was denoted by $c$ (the total effect), the path of predictor to mediator was denoted by $a$ and the path of mediator to outcome was denoted by $b$. The indirect effect was represented by the combined effect of paths $a$ and $b$, and the direct effect of predictor to outcome after the inclusion of the mediator in the model was denoted by $c^{\prime}$. The mediation effect was assessed by the bootstrapping procedure $(10,000$ samples), which provides accelerated confidence intervals $(95 \% \mathrm{CI}) . P_{M}$ (i.e., the ratio of indirect effect to total effect) was considered as the mediation effect measure (Wen \& Fan, 2015). Because of multiple testing, the $p$ values were corrected by applying the Bonferroni correction (level of significance: $p<.05$; Field, 2013).

\section{Ethics}

The study procedures were carried out in accordance with the Declaration of Helsinki. Responsible Ethics Committee of the Rehabilitation Center Seehof approved implementation of this study. All subjects were informed about the study and all provided informed consent.

\section{RESULTS}

Table 1 presents descriptive statistics of the investigated variables at $\mathrm{T} 1$ and at $\mathrm{T} 2$, as well as results of the withinsubject ANOVAs. According to the ANOVAs, the mean level of depressiveness, insomnia, and duration of daily Facebook use was significantly lower at T2 than at T1. At T1, 64 (18.3\%) inpatients daily spent over an hour with Facebook activity; whereas at T2, this figure declined to 31 $(8.9 \%)$ inpatients (see Table 1$)$. The decrease of the mean score of addictive Facebook use between T1 and T2 was not significant. The mean level of PMH was significantly higher at $\mathrm{T} 2$ than at $\mathrm{T} 1$.

Correlations between the investigated variables at both measurement time points are shown in Table 2. The score of addictive Facebook use at T1 was significantly positively linked to depressiveness and duration of daily Facebook use at $\mathrm{T} 1$ and at $\mathrm{T} 2$, and to insomnia at $\mathrm{T} 2$. Its correlation with $\mathrm{PMH}$ at both measurement time points was significantly negative. The score of addictive Facebook use at T2 was significantly positively linked to depressiveness at T1, and to duration of daily Facebook use at $\mathrm{T} 1$ and at T2. Its correlation with $\mathrm{PMH}$ at $\mathrm{T} 1$ and at $\mathrm{T} 2$ was significantly negative. At both measurement time points, $\mathrm{PMH}$ was significantly negatively correlated with depressiveness and insomnia, which were positively interrelated. Duration of daily Facebook use at T1 was significantly positively correlated with depressiveness at $\mathrm{T} 1$ and at $\mathrm{T} 2$, and with insomnia at T2. Its correlation with PMH at both measurement time points was significantly negative. Duration of daily Facebook use at T2 was significantly positively correlated with depressiveness at $\mathrm{T} 2$, and significantly negatively with $\mathrm{PMH}$ at $\mathrm{T} 1$ and at $\mathrm{T} 2$.

As presented in Table 3, in the first model, duration of daily Facebook use at T1 served as a significant positive predictor of the score of addictive Facebook use at T2. It added predictive variance of $35 \%$ for the score of addictive Facebook use at T2. In the other three models (see Table 3), the score of addictive Facebook use at T1 turned out to be a 
Table 1. Mean, SD, minimum, maximum, and repeated measures ANOVAs (T1 vs. T2) of all investigated variables

\begin{tabular}{|c|c|c|c|c|c|c|c|}
\hline & \multicolumn{2}{|c|}{$\mathrm{T} 1$} & \multicolumn{2}{|c|}{$\mathrm{T} 2$} & \multirow[b]{2}{*}{$F$} & \multirow[b]{2}{*}{$p$} & \multirow[b]{2}{*}{ Partial $\eta^{2}$} \\
\hline & $M(S D)$ & Min-Max & $M(S D)$ & Min-Max & & & \\
\hline Depressiveness & $26.64(11.48)$ & $0-56$ & $13.41(11.49)$ & $0-52$ & 673.957 & $<.001$ & .659 \\
\hline Insomnia & $15.74(6.38)$ & $0-28$ & $12.20(6.37)$ & $0-28$ & 177.449 & $<.001$ & .338 \\
\hline PMH & $10.07(5.97)$ & $0-26$ & $13.70(6.81)$ & $0-27$ & 156.047 & $<.001$ & .310 \\
\hline Daily FB use & $2.79(1.83)$ & $1-7$ & $2.32(1.43)$ & $1-7$ & 43.542 & $<.001$ & .111 \\
\hline Addictive FB use & $12.76(6.73)$ & $6-28$ & $12.39(6.42)$ & $6-29$ & 3.127 & .078 & .009 \\
\hline
\end{tabular}

Note. N: 349; FB: Facebook; T1: first measurement time point; T2: second measurement time point; $M$ : mean, $S D$ : standard deviation; Min: minimum; Max: maximum; degrees of freedom of all $F$ values $=1,348$, effect size: Partial $\eta^{2}$.

Table 2. Correlations of investigated variables (T1 and $\mathrm{T} 2$ )

\begin{tabular}{|c|c|c|c|c|c|c|c|c|c|}
\hline & (2) & (3) & (4) & (5) & (6) & (7) & (8) & (9) & (10) \\
\hline (1) Depressiveness T1 & $.497 * *$ & $-.672 * *$ & $.233 * *$ & $.205^{* *}$ & $.656^{* *}$ & $.406^{* *}$ & $-.640^{* *}$ & $.150 *$ & .136 \\
\hline (2) Insomnia T1 & & $-.404 * *$ & .140 & .122 & $.374 * *$ & $.697 * *$ & $-.371 * *$ & .087 & .086 \\
\hline (3) $\mathrm{PMH} \mathrm{T1}$ & & & $-.295 * *$ & $-.198 * *$ & $-.523 * *$ & $-.350 * *$ & $.647 * *$ & $-.214 * *$ & $-.152 * *$ \\
\hline (4) Addictive FB use T1 & & & & $.749 * *$ & $.248 * *$ & $.194 * *$ & $-.240 * *$ & $.827 * *$ & $.518^{* *}$ \\
\hline (5) Daily FB use T1 & & & & & $.258 * *$ & $.166^{* *}$ & $-.207 * *$ & $.591 * *$ & $.684 * *$ \\
\hline (6) Depressiveness T2 & & & & & & $.511 * *$ & $-.793 * *$ & .127 & $.256^{* *}$ \\
\hline (7) Insomnia $\mathrm{T} 2$ & & & & & & & $-.493 * *$ & .125 & .144 \\
\hline (8) $\mathrm{PMH} \mathrm{T} 2$ & & & & & & & & $-.158 * *$ & $-.190 * *$ \\
\hline (9) Addictive FB use T2 & & & & & & & & & $.438 * *$ \\
\hline (10) Daily FB use T2 & & & & & & & & & \\
\hline
\end{tabular}

Note. $N=349$. Correlations including addictive Facebook use are marked in bold. PMH: positive mental health; FB: Facebook; T1: first measurement time point; $\mathrm{T} 2$ : second measurement time point.

${ }^{* *} p<.01 .{ }^{*} p<.05$.

Table 3. Hierarchical regression analyses predicting addictive Facebook use at T2 and mental health at T2

\begin{tabular}{|c|c|c|c|c|c|}
\hline & $\beta$ & {$[95 \% \mathrm{CI}]$} & $T$ & Adjusted $R^{2}$ & Changes in $R^{2}$ \\
\hline \multicolumn{6}{|l|}{ Model 1: Addictive FB use T2 } \\
\hline Step $1, F(2,346)=0.846, p=.430$ & & & & -.001 & \\
\hline Age & .070 & {$[-0.024,0.120]$} & 1.301 & & \\
\hline Gender & .007 & {$[-1.391,1.573]$} & 0.121 & & \\
\hline Step $2, F(3,345)=62.762, p<.001$ & & & & .347 & .348 \\
\hline Duration of daily FB use $\mathrm{T} 1$ & $.590 * *$ & {$[1.771,2.369]$} & 13.627 & & \\
\hline \multicolumn{6}{|l|}{ Model 2: Depressiveness T2 } \\
\hline Step $1, F(2,346)=0.482, p=.618$ & & & & -.003 & \\
\hline Age & -.010 & {$[-0.141,0.118]$} & -0.177 & & \\
\hline Gender & .051 & {$[-1.372,3.938]$} & 0.950 & & \\
\hline Step $2, F(3,345)=7.936, p<.001$ & & & & .056 & .062 \\
\hline Addictive FB use $\mathrm{T} 1$ & $.249 * *$ & {$[0.250,0.601]$} & 4.773 & & \\
\hline \multicolumn{6}{|l|}{ Model 3: Insomnia T2 } \\
\hline Step $1, F(2,346)=3.857, p<.05$ & & & & .016 & \\
\hline Age & $.145^{* *}$ & {$[0.027,0.170]$} & 2.728 & & \\
\hline Gender & -.017 & {$[-1.699,1.219]$} & -0.323 & & \\
\hline Step $2, F(3,345)=6.842, p<.001$ & & & & .048 & .034 \\
\hline Addictive FB use $\mathrm{T} 1$ & $.186^{* *}$ & {$[0.078,0.274]$} & 3.543 & & \\
\hline \multicolumn{6}{|l|}{ Model 4: PMH T2 } \\
\hline Step $1, F(2,346)=0.865, p=0.422$ & & & & -.001 & \\
\hline Age & .051 & {$[-0.039,0.114]$} & 0.956 & & \\
\hline Gender & -.045 & {$[-2.238,0.907]$} & -0.832 & & \\
\hline Step $2, F(3,345)=7.884, p<.001$ & & & & .056 & .059 \\
\hline Addictive FB use T1 & $-.244 * *$ & {$[-0.351,-0.143]$} & -4.671 & & \\
\hline
\end{tabular}

Note. $N=349$. In Step 2, only the newly included variable is presented. PMH: positive mental health; FB: Facebook; $\beta$ : standardized coefficient beta; CI: confidence interval.

${ }^{* *} p<.01 .{ }^{*} p<.05$. 

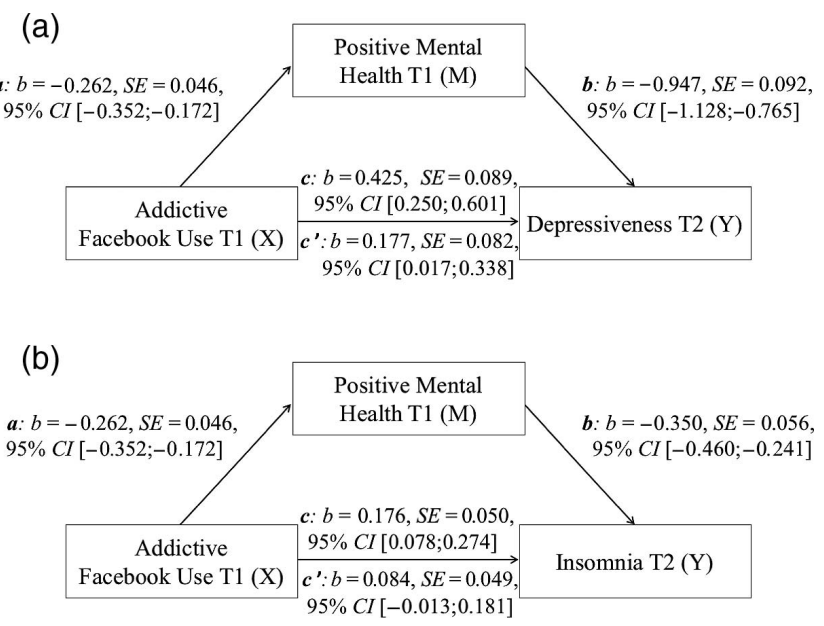

Figure 3. (a) Mediation model including addictive Facebook use at

$\mathrm{T} 1(\mathrm{X})$, positive mental health $(\mathrm{M})$, and depression $(\mathrm{Y})$;

(b) Mediation model including addictive Facebook use at T1 (X), positive mental health $(\mathrm{M})$, and insomnia $(\mathrm{Y})$. Note. $c$ : total effect, $c^{\prime}$ : direct effect; $b$ : standardized regression coefficient, $S E$ : standard error, CI: confidence interval

significant predictor of the mental health variables. It added predictive variance at $\mathrm{T} 2$ of $6.2 \%$ for depressiveness, of $3.4 \%$ for insomnia, and of $5.9 \%$ for PMH. Note that the investigated variables of mental health are complex constructs, which may be influenced by a high plurality of factors. The single effect of each factor is mostly small (Keyes, 2005). This is also reflected by current findings of the regression analyses.

Figure 3 shows results of both mediation analyses. In the first model (see Figure 3a), the total effect $(c: b=0.425$, $p<.0001)$ and the direct effect $\left(c^{\prime}: b=0.177, p=.0307\right)$ were significant, which may indicate that $\mathrm{PMH}$ at T1 partially mediated the association between the score of addictive Facebook use at $\mathrm{T} 1$ and depressiveness at T2. The indirect effect $(a b)$ was significant, $b=0.248,95 \% \mathrm{CI}=[0.164$, 0.339 ]; $P_{M}: b=0.583,95 \% \mathrm{CI}=[0.382,0.959]$.

In the second model (see Figure $3 \mathrm{~b}$ ), the total effect was significant $(c: b=.176, p=.0004)$, but not the direct effect $\left(c^{\prime}: b=0.084, p=.0885\right)$. This may indicate that PMH at T1 fully mediated the association between the score of addictive Facebook use at T1 and insomnia at T2. The indirect effect $(a b)$ was significant, $b=0.092,95 \% \mathrm{CI}=[0.055$, $0.140] ; P_{M}: b=0.521,95 \% \mathrm{CI}=[0.279,1.279]$.

\section{DISCUSSION}

In this study, for the first time, the conceptual framework of addictive Facebook use was investigated longitudinally in an inpatient sample. Our significant results, which correspond with the hypotheses, suggest that it might be relevant to assess and consider addictive Facebook use in the clinical context.

The research question referred to potential changes of addictive Facebook use between both measurement time points (see Research Question). We observed a decreasing trend between addictive Facebook use at T1 and at T2 $(p=.078)$, which however was not significant.
Note that the duration of daily Facebook use significantly decreased between both measurement time points. This may be explained by the advice to reduce the use of technical devices given to all inpatients and the variety of therapeutic and social activities offered during the stay in the psychosomatic clinic. Previous cross-sectional research indicated that duration of Facebook use contributed positively to the level of addictive Facebook use (Brailovskaia, Schillack, et al., 2018; Koc \& Gulyagci, 2013). Accordingly, in this study, at T1 and at T2, duration of daily Facebook use was positively related to addictive Facebook use. In addition, the results of the regression analysis revealed that the duration of Facebook use at T1 moreover contributed to the predictive variance of addictive Facebook use at T2 (confirmation of Hypothesis 1). Nevertheless, reduction of the duration of daily Facebook use was not sufficient to significantly reduce the level of addictive Facebook use from T1 to T2. Several interrelated reasons might explain this finding.

First, daily compliance with the advice to reduce the use of technical devices and specifically the use of Facebook was not systematically controlled during the clinical stay. It may be assumed that if this advice would be reinforced within psychoeducation or other parts of the therapeutic process supplemented by a systematic instructed and controlled reduction of Facebook use, risk of enhanced level of addictive Facebook use would decrease. Second, it could be that decrease of the level of addictive Facebook use is a slow process, which only becomes visible after a longer period of time than on average 6 weeks spent by the inpatients in the clinic. More specifically, for example, reduction of interpersonal conflicts at home and at work that belong to the six main characteristics of addictive Facebook use can mainly be noticed after the clinical stay. Third, despite the positive link between duration of Facebook use and addictive Facebook use, there can be further variables that impact the level of addictive Facebook use, such as the inpatients' level of flow (see Csikszentmihalyi, 1990) experienced during the Facebook use, which was previously described to be a significant antecedent of problematic Facebook use in healthy individuals (Brailovskaia, Rohmann, Bierhoff, \& Margraf, 2018). Moreover, considering that the sample consists of inpatients, it may also be that their general symptoms as well as their comorbidities affect the results.

Besides the Facebook variables, the results presented in Table 1 reveal that the mental health status of the inpatients improved from the first to the second measurement time points. While the level of depressiveness and insomnia that represent the negative dimension of mental health decreased, the level of PMH level that represents the positive dimension increased. Those changes may, on the one hand, directly date from the clinical treatment. On the other hand, during the clinical stay, all participants experience a change of their familiar environment. Particularly for individuals who are used to experience a high level of daily stress at home and at work, the change of the environment and the avoidance of their daily routine may foster the enhancement of mental health and therefore contribute to the explanation of present findings. Considering that depressiveness and insomnia are positively linked to the main disorders the inpatients suffer from (Abad \& Guilleminault, 2005; 
Zisook et al., 2006), and PMH was previously shown to be a protective factor that may reduce negative symptoms (Teismann, Brailovskaia, Totzeck, et al., 2018; Teismann, Forkmann, et al., 2018), those changes are of great importance for the success of the clinical treatment and the overall recovery process of inpatients.

Current results revealed that addictive Facebook use was positively associated with depressiveness and insomnia. Its relationship with $\mathrm{PMH}$ was negative. Moreover, in accordance with the expectations, the results of the regression analyses showed that addictive Facebook use at T1 contributed to the predictive variance of depressiveness at T2, of insomnia at $\mathrm{T} 2$, and of $\mathrm{PMH}$ at $\mathrm{T} 2$ (confirmation of Hypotheses $2 a-2 c$ ). These longitudinal findings allow the assumption that addictive Facebook use might be a risk factor for the success of therapeutic results. Longitudinally, participation at the Facebook world, which offers attractive possibilities for social interaction and self-presentation, seems to foster addictive tendencies. Typical characteristics of addictive Facebook use, such as salience of Facebook activity, conflict, and withdrawal when the SNS cannot be used, might negatively impact affected individuals. In the clinical setting, inpatients with enhanced level of addictive Facebook use inter alia might get into conflict with therapists or other inpatients because of the neglect of responsibilities such as punctual appearance in the daily therapy sessions. Presumably, they might pay less attention to what is happening around them in the offline world and therefore they might be likely to profit less from the clinical stay than others. Therefore, they might feel sad, guilty, and pessimistic symptoms of depressiveness. Furthermore, they might try to compensate for the time of Facebook non-usage during the day by intensive Facebook activity at bedtime, which is likely to negatively impact their sleep-wake rhythm and to foster insomnia. All these symptoms might restrict the expected recovery process.

On the background of previous research, our current results seem to indicate a possibility to reduce the negative impact of addictive Facebook use. Earlier studies revealed $\mathrm{PMH}$ to be a protective factor that inter alia reduces suicide risk (e.g., Teismann, Forkmann, et al., 2018) and contributes to the remission of mental disorders (e.g., Lukat et al., 2017). Our present findings complement previous results by showing that PMH at T1 (partially) mediates the effect of addictive Facebook use at T1 on depressiveness at T2 (confirmation of Hypothesis 3a) and on insomnia at T2 (confirmation of Hypothesis $3 b$ ). Accordingly, $\mathrm{PMH}$ confers resilience against depressiveness and insomnia, which both foster maintenance of mental disorders. As a consequence, PMH may contribute to the treatment success and the recovery process of the inpatients. Thus, the level of PMH should be strengthened during the clinical stay (see Lukat et al., 2017), for example, by interventions that focus on the enhancement of individual problem-solving abilities (Bell \& D'Zurilla, 2009; D'Zurilla \& Nezu, 2007), self-efficacy (Kuss \& Pontes, 2019; Schönfeld, Brailovskaia, Zhang, \& Margraf, 2018), and flexibility (Kashdan \& Rottenberg, 2010). Those factors contribute positively to the level of PMH and enhance the personal capability to cope adequately with daily stressors (instead of escaping into the online world), which might in turn foster the decrease of addictive Facebook use.

\section{Limitations and further research}

First, due to the restricted range of diagnoses in the present sample, it remains unclear whether our findings may be generalized to inpatients with other diagnoses, such as eating disorders or schizophrenia. This should be investigated in future inpatient studies. In addition, the study participants were treated differently during their clinical stay depending on the diagnosed disorder. Therefore, the results are based on several widespread disorders. Further studies are needed to investigate the relationship between (addictive) Facebook use and the effect of therapeutic treatment on inpatients' main disorders and to control for comorbidities that might impact the mental health status and also might interact with the Facebook activity.

Second, since we investigated only inpatients, future research should clarify whether similar results emerge in a sample of outpatients. It might be hypothesized that associations between addictive Facebook use and the negative mental health variables are stronger in outpatients who often lack social support from their close network and cannot benefit from the social interactions and the therapeutic supervision provided in the protected clinical context to the same extent as inpatients.

Third, in this study, data were assessed only at two measurement time points within a 6-week period during the clinical stay of the inpatients. To obtain evidence with respect to the investigated variables and their relationships on longitudinal changes over a longer period, future studies are suggested to replicate our findings by the inclusion of additional measurement time points (e.g., 6 months or 1 year after the clinical stay).

Fourth, previous research reported specific use preferences such as writing of status updates and gaming via Facebook to be positively linked to the level of addictive/ problematic Facebook use (Rothen et al., 2018). The authors emphasized that Facebook use is not addictive per se and that it is important to distinguish between different activities that users perform on the SNS. Therefore, we suggest future research not only to focus on the duration of Facebook use, but also to consider the specific content of use to identify particular predictors of addictive tendencies.

Fifth, due to the high popularity of the social platform Facebook (Roth, 2019) that enables its users a high variety of functions that imply considerable potential for addictive symptoms, only addictive use of this SNS was investigated in this study. However, the enhanced popularity of other SNSs in the past years (Alhabash \& Ma, 2017) should not be ignored. Several recent studies reported addictive/ problematic use of such social platforms, such as Instagram (Kircaburun \& Griffiths, 2018), Twitter (Kircaburun, 2016), and Snapchat (Punyanunt-Carter, De La Cruz, \& Wrench, 2017). Therefore, future studies are advised to investigate whether present findings may be generalized with respect to problematic use on alternative social platforms or whether they are specific for Facebook.

Sixth, the time span between T1 and T2 varied between 21 and 42 days. Referring to future longitudinal research, it would be interesting to investigate the association between time span and changes in the level of Facebook use and the mental health variables between measurement points systematically. 


\section{CONCLUSIONS}

To sum up, our results suggest that duration of daily Facebook activity and addictive Facebook use might negatively impact the inpatients' recovery process and therefore should be assessed and considered when planning the therapeutic treatment. Simultaneously, enhancement of PMH that may buffer the negative effect of addictive Facebook use and support the recovery process should be included within the clinical interventions.

Funding sources: The authors would like to acknowledge support by the DFG Open Access Publication Funds of the Ruhr-Universität Bochum.

Authors' contribution: JB, VK, and JM prepared the study concept and design. JB conducted statistical analysis, interpretation of data, and wrote the first draft of the manuscript. JB and VK conducted supervision of study. $\mathrm{ER}, \mathrm{H}-\mathrm{WB}$, and VK reviewed and edited the first draft. All authors had full access to all data in the study and take responsibility for the integrity of the data and the accuracy of the data analysis.

Conflict of interest: The authors declare no conflict of interest.

\section{REFERENCES}

Abad, V. C., \& Guilleminault, C. (2005). Sleep and psychiatry. Dialogues in Clinical Neuroscience, 7(4), 291-303.

Alhabash, S., \& Ma, M. (2017). A tale of four platforms: Motivations and uses of Facebook, Twitter, Instagram, and Snapchat among college students? Social Media + Society, 3(1), 1-13. doi:10.1177/2056305117691544

American Psychiatric Association. (2013). Diagnostic and statistical manual of mental disorders (5th ed.). Washington, DC: American Psychiatric Association.

Andreassen, C. S., Billieux, J., Griffiths, M. D., Kuss, D. J., Demetrovics, Z., Mazzoni, E., \& Pallesen, S. (2016). The relationship between addictive use of social media and video games and symptoms of psychiatric disorders: A large-scale cross-sectional study. Psychology of Addictive Behaviors, 30(2), 252-262. doi:10.1037/adb0000160

Andreassen, C. S., Griffiths, M. D., Gjertsen, S. R., Krossbakken, E., Kvam, S., \& Pallesen, S. (2013). The relationships between behavioral addictions and the five-factor model of personality. Journal of Behavioral Addictions, 2(2), 90-99. doi:10.1556/ JBA.2.2013.003

Andreassen, C. S., Torsheim, T., Brunborg, G. S., \& Pallesen, S. (2012). Development of a Facebook Addiction Scale. Psychological Reports, 110(2), 501-517. doi:10.2466/02.09.18.PR0. 110.2.501-517

Atroszko, P. A., Balcerowska, J. M., Bereznowski, P., Biernatowska, A., Pallesen, S., \& Andreassen, C. S. (2018). Facebook addiction among Polish undergraduate students: Validity of measurement and relationship with personality and well-being. Computers in Human Behavior, 85, 329-338. doi:10.1016/j.chb.2018. 04.001

Bányai, F., Zsila, Á., Király, O., Maraz, A., Elekes, Z., Griffiths, M. D., Andreassen, C. S., \& Demetrovics, Z. (2017). Problematic social media use: Results from a large-scale nationally representative adolescent sample. PLoS One, 12(1), e0169839. doi:10.1371/journal.pone.0169839

Bastien, C. H., Vallières, A., \& Morin, C. M. (2001). Validation of the Insomnia Severity Index as an outcome measure for insomnia research. Sleep Medicine, 2(4), 297-307. doi:10.1016/S13899457(00)00065-4

Bell, A. C., \& D'Zurilla, T. J. (2009). Problem-solving therapy for depression: A meta-analysis. Clinical Psychology Review, 29(4), 348-353. doi:10.1016/j.cpr.2009.02.003

Billieux, J., Schimmenti, A., Khazaal, Y., Maurage, P., \& Heeren, A. (2015). Are we overpathologizing everyday life? A tenable blueprint for behavioral addiction research. Journal of Behavioral Addictions, 4(3), 119-123. doi:10.1556/2006.4.2015.009

Błachnio, A., Przepiorka, A., Benvenuti, M., Cannata, D., Ciobanu, A. M., Senol-Durak, E., Durak, M., Giannakos, M. N., Mazzoni, E., Pappas, I. O., Popa, C., Seidman, G., Yu, S., Wu, A. M. S., \& Ben-Ezra, M. (2016). An international perspective on Facebook intrusion. Psychiatry Research, 242, 385-387. doi:10.1016/j.psychres.2016.06.015

Błachnio, A., Przepiórka, A., \& Pantic, I. (2015). Internet use, Facebook intrusion, and depression: Results of a crosssectional study. European Psychiatry, 30(6), 681-684. doi:10.1016/j.eurpsy.2015.04.002

Brailovskaia, J., \& Bierhoff, H.-W. (2016). Cross-cultural narcissism on Facebook: Relationship between self-presentation, social interaction and the open and covert narcissism on a social networking site in Germany and Russia. Computers in Human Behavior, 55, 251-257. doi:10.1016/j.chb.2015. 09.018

Brailovskaia, J., \& Margraf, J. (2016). Comparing Facebook users and Facebook non-users: Relationship between personality traits and mental health variables - An exploratory study. PLoS One, 11(12), e0166999. doi:10.1371/journal.pone. 0166999

Brailovskaia, J., \& Margraf, J. (2017). Facebook Addiction Disorder (FAD) among German students - A longitudinal approach. PLoS One, 12(12), e189719. doi:10.1371/journal.pone.0189719

Brailovskaia, J., \& Margraf, J. (2018). What does media use reveal about personality and mental health? An exploratory investigation among German students. PLoS One, 13(1), e0191810. doi:10.1371/journal.pone.0191810

Brailovskaia, J., \& Margraf, J. (2019). I present myself and have a lot of Facebook-friends-Am I a happy narcissist!? Personality and Individual Differences, 148, 11-16. doi:10.1016/j.paid. 2019.05.022

Brailovskaia, J., Margraf, J., \& Köllner, V. (2019). Addicted to Facebook? Relationship between Facebook Addiction Disorder, duration of Facebook use and narcissism in an inpatient sample. Psychiatry Research, 273, 52-57. doi:10.1016/j. psychres.2019.01.016

Brailovskaia, J., Rohmann, E., Bierhoff, H.-W., \& Margraf, J. (2018). The brave blue world: Facebook flow and Facebook Addiction Disorder (FAD). PLoS One, 13(7), e0201484. doi:10.1371/journal.pone.0201484

Brailovskaia, J., Schillack, H., \& Margraf, J. (2018). Facebook Addiction Disorder (FAD) in Germany. Cyberpsychology, 
Behavior, and Social Networking, 21(7), 450-456. doi:10.1089/cyber.2018.0140

Brailovskaia, J., Schönfeld, P., Zhang, X. C., Bieda, A., Kochetkov, Y., \& Margraf, J. (2018). A Cross-cultural study in Germany, Russia, and China: Are resilient and social supported students protected against depression, anxiety, and stress? Psychological Reports, 121(2), 265-281. doi:10.1177/ 0033294117727745

Brailovskaia, J., Teismann, T., \& Margraf, J. (2018a). Cyberbullying, positive mental health and suicide ideation/behavior. Psychiatry Research, 267, 240-242. doi:10.1016/j.psychres. 2018.05.074

Brailovskaia, J., Teismann, T., \& Margraf, J. (2018b). Physical activity mediates the association between daily stress and Facebook Addiction Disorder (FAD) - A longitudinal approach among German students. Computers in Human Behavior, 86, 199-204. doi:10.1016/j.chb.2018.04.045

Casale, S., \& Fioravanti, G. (2018). Why narcissists are at risk for developing Facebook addiction: The need to be admired and the need to belong. Addictive Behaviors, 76, 312-318. doi:10.1016/j.addbeh.2017.08.038

Csikszentmihalyi, M. (1990). Flow: The psychology of optimal performance. New York, NY: Cambridge University Press.

D'Zurilla, T. J., \& Nezu, A. M. (2007). Problem-solving therapy: A positive approach to clinical intervention. New York, NY: Springer.

Fernandez, K. C., Levinson, C. A., \& Rodebaugh, T. L. (2012). Profiling: Predicting social anxiety from Facebook profiles. Social Psychological and Personality Science, 3(6), 706-713. doi:10.1177/1948550611434967

Field, A. (2013). Discovering statistics using IBM SPSS statistics. London, UK: Sage Publications Ltd.

Frost, R. L., \& Rickwood, D. J. (2017). A systematic review of the mental health outcomes associated with Facebook use. Computers in Human Behavior, 76, 576-600. doi:10.1016/ j.chb.2017.08.001

George, D., \& Mallery, M. (2010). SPSS for windows step by step: A simple guide and reference, 17.0 update (10th ed.). Boston, MA: Pearson.

Gravetter, F. J., \& Wallnau, L. B. (2014). Statistics for the behavioral sciences (10th ed.). Boston, MA: Cengage Learning.

Griffiths, M. D. (2005). A 'components' model of addiction within a biopsychosocial framework. Journal of Substance Use, 10(4), 191-197. doi:10.1080/14659890500114359

Hautzinger, M., Keller, F., \& Kühner, C. (2009). Beck DepressionsInventar (BDI-II; Revision; 2. Aufl.) [Beck Depression Inventary (BDI-II revised; 2nd edition)]. Göttingen, Germany: PsychCorp.

Hong, F.-Y., Huang, D.-H., Lin, H.-Y., \& Chiu, S.-L. (2014). Analysis of the psychological traits, Facebook usage, and Facebook addiction model of Taiwanese university students. Telematics and Informatics, 31(4), 597-606. doi:10.1016/ j.tele.2014.01.001

Indian, M., \& Grieve, R. (2014). When Facebook is easier than face-to-face: Social support derived from Facebook in socially anxious individuals. Personality and Individual Differences, 59, 102-106. doi:10.1016/j.paid.2013.11.016

Kashdan, T. B., \& Rottenberg, J. (2010). Psychological flexibility as a fundamental aspect of health. Clinical Psychology Review, 30(7), 865-878. doi:10.1016/j.cpr.2010.03.001

Keyes, C. L. (2005). Mental illness and/or mental health? Investigating axioms of the complete state model of health. Journal of
Consulting and Clinical Psychology, 73(3), 539-548. doi:10.1037/0022-006X.73.3.539

Keyes, C. L., Shmotkin, D., \& Ryff, C. D. (2002). Optimizing well-being: The empirical encounter of two traditions. Journal of Personality and Social Psychology, 82(6), 1007-1022. doi:10.1037/0022-3514.82.6.1007

Kircaburun, K. (2016). Effects of gender and personality differences on Twitter addiction among Turkish undergraduates. Journal of Education and Practice, 7(24), 33-42.

Kircaburun, K., \& Griffiths, M. D. (2018). Instagram addiction and the Big Five of personality: The mediating role of self-liking. Journal of Behavioral Addictions, 7(1), 158-170. doi:10.1556/ 2006.7.2018.15

Koc, M., \& Gulyagci, S. (2013). Facebook addiction among Turkish college students: The role of psychological health, demographic, and usage characteristics. Cyberpsychology, Behavior, and Social Networking, 16(4), 279-284. doi:10.1089/ cyber.2012.0249

Köllner, V. (2014). Psychosomatische rehabilitation. Psychotherapeut, 59(6), 485-502. doi:10.1007/s00278-014-1085-x

Kuss, D. J., \& Griffiths, M. (2017). Social networking sites and addiction: Ten lessons learned. International Journal of Environmental Research and Public Health, 14(3), 311-328. doi:10.3390/ijerph14030311

Kuss, D. J., \& Pontes, H. M. (2019). Internet addiction. Advances in Psychotherapy - Evidence-Based Practice, 41, 1-79.

Linden, M. (2014). Psychosomatic inpatient rehabilitation: The German model. Psychotherapy and Psychosomatics, 83(4), 205-212. doi:10.1159/000358852

Lovibond, P. F., \& Lovibond, S. H. (1995). The structure of negative emotional states: Comparison of the Depression Anxiety Stress Scales (DASS) with the Beck Depression and Anxiety Inventories. Behaviour Research and Therapy, 33(3), 335-343. doi:10.1016/0005-7967(94)00075-U

Lukat, J., Becker, E. S., Lavallee, K. L., van der Veld, W. M., \& Margraf, J. (2017). Predictors of incidence, remission and relapse of Axis I mental disorders in young women: A transdiagnostic approach. Clinical Psychology \& Psychotherapy, 24(2), 322-331. doi:10.1002/cpp.2026

Lukat, J., Margraf, J., Lutz, R., van der Veld, W. M., \& Becker, E. S. (2016). Psychometric properties of the Positive Mental Health Scale (PMH-scale). BMC Psychology, 4(1), 8. doi:10.1186/s40359-016-0111-x

Marino, C., Gini, G., Vieno, A., \& Spada, M. M. (2018). A comprehensive meta-analysis on problematic Facebook use. Computers in Human Behavior, 83, 262-277. doi:10.1016/ j.chb.2018.02.009

Mayr, S., Erdfelder, E., Buchner, A., \& Faul, F. (2007). A short tutorial of GPower. Tutorials in Quantitative Methods for Psychology, 3(2), 51-59. doi:10.20982/tqmp.03.2.p051

Muschalla, B., Kessler, U., Schwantes, U., \& Linden, M. (2013). Rehabilitationsbedarf bei Hausarztpatienten mit psychischen Störungen [Medical rehabilitation by general practitioners in patients with chronic mental disorders]. Die Rehabilitation, 52(04), 251-256. doi:10.1055/s-0032-1327587

Papacharissi, Z., \& Mendelson, A. (2011). Toward a new(er) sociability: Uses, gratifications and social capital on Facebook. In S. Papathanassopoulos (Ed.), Media perspectives for the 21st century (pp. 212-230). Oxon, UK: Routledge.

Punyanunt-Carter, N. M., De La Cruz, J. J., \& Wrench, J. S. (2017). Investigating the relationships among college students' 
satisfaction, addiction, needs, communication apprehension, motives, and uses \& gratifications with Snapchat. Computers in Human Behavior, 75, 870-875. doi:10.1016/j.chb.2017.06.034

Raacke, J., \& Bonds-Raacke, J. (2008). MySpace and Facebook: Applying the uses and gratifications theory to exploring friend-networking sites. CyberPsychology \& Behavior, 11(2), 169-174. doi:10.1089/cpb.2007.0056

Roth, P. (2019, July 26). Nutzerzahlen: Facebook, Instagram, Messenger und WhatsApp, Highlights, Umsätze, uvm. allfaceook.de. Retrieved from https://allfacebook.de/toll/state-offacebook

Rothen, S., Briefer, J.-F., Deleuze, J., Karila, L., Andreassen, C. S., Achab, S., Thorens, G., Khazaal, Y., Zullino, D., \& Billieux, J. (2018). Disentangling the role of users' preferences and impulsivity traits in problematic Facebook use. PLoS One, 13(9), e0201971. doi:10.1371/journal.pone.0201971

Ryan, T., Chester, A., Reece, J., \& Xenos, S. (2014). The uses and abuses of Facebook: A review of Facebook addiction. Journal of Behavioral Addictions, 3(3), 133-148. doi:10.1556/JBA.3. 2014.016

Schönfeld, P., Brailovskaia, J., Zhang, X. C., \& Margraf, J. (2018). Self-efficacy as a mechanism linking daily stress to mental health in students: A three-wave cross-lagged study. Psychological Reports, 122(6), 2074-2095. doi:10.1177/003329 4118787496

Siegmann, P., Teismann, T., Fritsch, N., Forkmann, T., Glaesmer, H., Zhang, X. C., Brailovskaia, J., \& Margraf, J. (2017). Resilience to suicide ideation: A cross-cultural test of the buffering hypothesis. Clinical Psychology \& Psychotherapy, 25(1), e1-e9. doi:10.1002/cpp.2118

Sinclair, T. J., \& Grieve, R. (2017). Facebook as a source of social connectedness in older adults. Computers in Human Behavior, 66, 363-369. doi:10.1016/j.chb.2016.10.003

Teismann, T., Brailovskaia, J., Siegmann, P., Nyhuis, P., Wolter, M., \& Willutzki, U. (2018). Dual factor model of mental health: Co-occurrence of positive mental health and suicide ideation in inpatients and outpatients. Psychiatry Research, 260, 343-345. doi:10.1016/j.psychres.2017.11.085

Teismann, T., Brailovskaia, J., Totzeck, C., Wannemüller, A., \& Margraf, J. (2018). Predictors of remission from panic disorder, agoraphobia and specific phobia in outpatients receiving exposure therapy: The importance of positive mental health. Behaviour Research and Therapy, 108, 40-44. doi:10.1016/ j.brat.2018.06.006

Teismann, T., Forkmann, T., Brailovskaia, J., Siegmann, P., Glaesmer, H., \& Margraf, J. (2018). Positive mental health moderates the association between depression and suicide ideation: A longitudinal study. International Journal of Clinical and Health Psychology, 18(1), 1-7. doi:10.1016/ j.ijchp.2017.08.001

Tromholt, M. (2016). The Facebook experiment: Quitting Facebook leads to higher levels of well-being. Cyberpsychology,
Behavior, and Social Networking, 19(11), 661-666. doi:10.1089/ cyber.2016.0259

Trompetter, H. R., Lamers, S. M. A., Westerhof, G. J., Fledderus, M., \& Bohlmeijer, E. T. (2017). Both positive mental health and psychopathology should be monitored in psychotherapy: Confirmation for the dual-factor model in acceptance and commitment therapy. Behaviour Research and Therapy, 91, 58-63. doi:10.1016/j.brat.2017.01.008

Trumpf, J., Becker, E. S., Vriends, N., Meyer, A. H., \& Margraf, J. (2009). Rates and predictors of remission in young women with specific phobia: A prospective community study. Journal of Anxiety Disorders, 23(7), 958-964. doi:10.1016/j.janxdis. 2009.06.005

Twenge, J. M., Joiner, T. E., Rogers, M. L., \& Martin, G. N. (2018). Increases in depressive symptoms, suicide-related outcomes, and suicide rates among US adolescents after 2010 and links to increased new media screen time. Clinical Psychological Science, 6(1), 3-17. doi:10.1177/216770261 7723376

Urban, D., \& Mayerl, J. (2006). Regressionsanalyse: Theorie, Technik und Anwendung (2. Aufl.) [Regression analysis: Theory, procedure, and application (2nd edition)]. Wiesbaden, Germany: VS Verlag für Sozialwissenschaften.

Wen, Z., \& Fan, X. (2015). Monotonicity of effect sizes: Questioning kappa-squared as mediation effect size measure. Psychological Methods, 20(2), 193-203. doi:10.1037/met0000029

Wilson, K., Fornasier, S., \& White, K. M. (2010). Psychological predictors of young adults' use of social networking sites. Cyberpsychology, Behavior, and Social Networking, 13(2), 173-177. doi:10.1089/cyber.2009.0094

Wolniczak, I., Cáceres-DelAguila, J. A., Palma-Ardiles, G., Arroyo, K. J., Solís-Visscher, R., Paredes-Yauri, S., Mego-Aquije, K., \& Bernabe-Ortiz, A. (2013). Association between Facebook dependence and poor sleep quality: A study in a sample of undergraduate students in Peru. PLoS One, 8(3), e59087. doi:10.1371/journal.pone.0059087

Wright, K. B., Rosenberg, J., Egbert, N., Ploeger, N. A., Bernard, D. R., \& King, S. (2013). Communication competence, social support, and depression among college students: A model of Facebook and face-to-face support network influence. Journal of Health Communication, 18(1), 41-57. doi:10.1080/ 10810730.2012.688250

Zhang, J., Fang, L., Wu, Y.-W. B., \& Wieczorek, W. F. (2013). Depression, anxiety, and suicidal ideation among Chinese Americans: A study of immigration-related factors. The Journal of Nervous and Mental Disease, 201(1), 17-22. doi:10.1097/NMD.0b013e31827ab2e2

Zisook, S., Nyer, M., Kasckow, J., Golshan, S., Lehman, D., \& Montross, L. (2006). Depressive symptom patterns in patients with chronic schizophrenia and subsyndromal depression. Schizophrenia Research, 86(1-3), 226-233. doi:10.1016/ j.schres.2006.03.047 